\title{
Efeito de defensivos agrícolas naturais e extratos vegetais sobre parâmetros biológicos de Metarhizium anisopliae (Metsch.) Sorok
}

\author{
Effect of natural pesticides and plant extracts on biological \\ parameters of Metarhizium anisopliae (Metsch.) Sorok
}

\author{
Ana Paula Mamprim ${ }^{1}$; Luis Franscisco Angeli Alves ${ }^{2 *}$; \\ Fabiana Gisele da Silva Pinto ${ }^{3}$; Marina Andressa Formentini"; \\ Claudecir Castilho Martins ${ }^{5}$; Andréia Kusumota Bonini ${ }^{6}$
}

\begin{abstract}
Resumo
O objetivo deste trabalho foi avaliar a compatibilidade e os efeitos dos defensivos agrícolas naturais, extratos vegetais e basidiocarpos de Pycnoporus sanguineus, em diferentes concentrações, sobre o fungo entomopatogênico Metarhizium anisopliae. Os extratos e os basidiocarpos foram utilizados na concentração de $10 \%$. Os defensivos agrícolas foram utilizados na concentração rotulada (CR), a metade $(0,5 \mathrm{CR})$ e o dobro da mesma (2CR). Em todos os tratamentos foram realizadas pulverizações sobre o fungo inoculado previamente em meio de cultura (BDA). Foram avaliados germinação, Unidade Formadora de Colônia, crescimento vegetativo e produtividade dos conídios. Em relação aos defensivos agrícolas, somente o Calda Sulfocálcica na concentração recomendada e no dobro da mesma não se mostrou compatível, sendo considerada moderadamente tóxica para o fungo M. anisopliae. Apesar de os extratos terem apresentado efeito significativo principalmente sobre a viabilidade (redução de 50 a $80 \%$ por extratos alcoólicos), verificou-se a compatibilidade para todos os extratos. Contudo, deve-se evitar o uso conjunto em misturas ou aplicações subsequentes dos produtos aqui testados em menos de 48 horas após a aplicação do fungo.
\end{abstract}

Palavras-chave: Fungos entomopatogênicos, compatibilidade, produtos alternativos

\begin{abstract}
This study was carried out aiming to evaluate the effect and compatibility of vegetal and Pycnoporus sanguineus basidiocarps extracts and alternative products on biological parameters of Metarhizium anisopliae fungus. Extracts (solution in water 10\%) and natural products (AR = average field recommendation; $0.5 \mathrm{AR}$ and 2.0 AR) are applied on PDAculture media surface previously inoculated with fungi conidia. The effect of the treatment on conidia germination, vegetative growth and conidiogenesis was compared. Most alternative products were compatible to the fungus, and only Bordeaux mixture $\mathrm{AR}$ and 2.0 AR were moderately toxic to M. anisopliae. Although some significativally negative effect
\end{abstract}

${ }^{1}$ M.e. em Agronomia, Universidade Estadual do Oeste do Paraná, Centro de Ciências Biológicas e da Saúde, UNIOESTE/CCBS, Laboratório de Biotecnologia Agrícola, Campus Cascavel, Cascavel, PR. E-mail: anamamprim@hotmail.com

${ }^{2}$ Dr. em Entomologia, ESALQ, Prof. e pesquisador, UNIOESTE/CCBS, Cascavel, PR. E-mail: luis.alves@unioeste.br

${ }^{3} \mathrm{Dr}^{\mathrm{a}}$ em Microbiologia, UEL. Prof ${ }^{\mathrm{a}}$ e pesquisadora, UNIOESTE/CCBS, Cascavel, PR. E-mail: fabiana.pinto@unioeste.br

${ }^{4}$ Me. em Conservação e Manejo de Recursos Naturais, UNIOESTE/CCBS, Laboratório de Biotecnologia Agrícola, Campus Cascavel, Cascavel, PR. E-mail: marinaformentini@hotmail.com

${ }^{5}$ Discente de Mestrado em Conservação e Manejo de Recursos Naturais, UNIOESTE, CCBS, Laboratório de Biotecnologia Agrícola, Campus Cascavel, Cascavel, PR. E-mail:claudecirmartins@hotmail.com

${ }^{6}$ M.e. em Engenharia Agrícola, UNIOESTE, Campus de Cascavel, CCBS, Laboratório de Biotecnologia Agrícola, Cascavel, PR. E-mail: akbonini@yahoo.com.br

* Autor para correspondência 
there were observed on conidial viability (reduction of 50 to $80 \%$ by alcoholic extracts), all extracts were compatible. This point to the necessity to be careful with application, avoiding mixtures or subsequent use of products less than 48 hours after fungi application.

Key words: Entomopathogenic fungi, compatibility, alternative products

\section{Introdução}

Com o aumento da produtividade e do uso intensivo de produtos fitossanitários sintéticos, aumentam os problemas ambientais, já que muitos produtos são de amplo espectro de ação e persistentes no ambiente, causando desequilíbrio biológico, devido à ação sobre organismos não-alvo, incluindo agentes de controle biológico (AZEVEDO, 1998).

Para minimizar esses problemas, pesquisas com diversos produtos fitossanitários alternativos (PFA), têm sido desenvolvidas, envolvendo biofertilizantes (MEDEIROS et al., 2007), indutores de resistência (DANTAS et al., 2004) e de produtos naturais com partes de plantas, caldas, extratos cítricos, que possuem ação inseticida, antimicrobiana e repelência (HIROSE et al., 2001). Esses produtos, em relação à produção agrícola, mostram ser mais seguros e viáveis do ponto de vista da sustentabilidade, visto que podem ser mais seletivos aos inimigos naturais, preservando, desta forma, o controle biológico natural. Neste contexto, também se destacam os fungos entomopatogênicos, que são amplamente utilizados no controle biológico em várias culturas de importância agrícola (ALVES; MOINO; ALMEIDA, 1998; FARIA; MAGALHÃES, 2001).

Por outro lado, sabe-se que o sucesso dos fungos no controle de pragas é dependente da sobrevivência dos conídios no ambiente, e que pode ser afetada diretamente por fatores ambientais (FURLONG; PELL, 1997; ALVES; LECUONA, 1998) e também pelos produtos fitossanitários utilizados, até mesmo produtos naturais. Nesse sentido, Neves et al. (2001) e Alves et al. (2001) ressaltam a importância dos produtos fitossanitários sobre a germinação no estudo da compatibilidade, visto que a inibição da germinação compromete a eficiência do patógeno. Também, Marques, Monteiro e Pereira (2004),
Formentini (2009), e Mertz et al. (2010) estudaram a influência de produtos fitossanitários alternativos sobre o crescimento vegetativo, esporulação e germinação dos fungos entomopatogênicos, verificando em geral a compatibilidade entre os agentes de estudo.

Os estudos in vitro que avaliem a interação de produtos fitossanitários sobre fungos entomopatogênicos são imprescindíveis para a determinação de estratégias adequadas de utilização dos entomopatógenos no controle de pragas, notadamente em programas de manejo integrado, visto que estes produtos podem influenciar os microrganismos, modificando, conseqüentemente, a sua ação. Contudo, especificamente em relação aos PFA, há pouca informação disponível.

Assim, o objetivo deste trabalho foi avaliar o efeito de defensivos agrícolas naturais e extratos vegetais sobre parâmetros biológicos do fungo Metarhizium anisopliae.

\section{Material e Métodos}

Obtenção dos produtos e extratos. Foram avaliados produtos comerciais alternativos escolhidos por serem utilizados em sistemas de produção agroecológicos ou orgânicos, como indutores de resistência, inseticidas e fungicidas, obtidos em lojas de insumos agrícolas, sendo que as concentrações utilizadas foram as estabelecidas nos rótulos dos produtos, a metade e o dobro da mesma (Tabela 1).

Foram também avaliados extratos aquosos e alcoólicos de plantas e aquoso de basidiocarpos do fungo Pycnoporus sanguineus (orelha de pau), na concentração de 10\% (Tabela 2). 
Tabela 1. Produtos alternativos comerciais utilizados nos experimentos com respectiva composição, concentração e atividade biológica.

\begin{tabular}{|c|c|c|c|}
\hline Produto & Composição/Nome científico ${ }^{1}$ & $\begin{array}{c}\text { Concentração } \\
\text { Recomendada/ha }{ }^{2}\end{array}$ & Indicação de uso \\
\hline Agro-Mos ${ }^{\circledR}$ & $\begin{array}{l}\text { Parede celular de Saccharomyces } \\
\text { cerevisiae/mananoligossacarídeos }\end{array}$ & $200 \mathrm{~mL} / 100 \mathrm{~L} \mathrm{H}_{2} \mathrm{O}$ & indutor de resistência \\
\hline Agro-Fos & $\begin{array}{l}\text { Rico em nutrientes, aminoácidos, } \\
\text { vitaminas e fosfito }\end{array}$ & $200 \mathrm{~mL} / 100 \mathrm{~L} \mathrm{H}_{2} \mathrm{O}$ & indutor de resistência \\
\hline Bion $^{\circledR}$ & Acibenzolar-s-metílico: $500 \mathrm{~g} / \mathrm{kg}$ & $80 \mathrm{~g} / 100 \mathrm{~L} \mathrm{H}_{2} \mathrm{O}$ & indutor de resistência \\
\hline Biogermex $^{\circledR}$ & Extratos cítricos & $200 \mathrm{~mL} / 100 \mathrm{~L} \mathrm{H}_{2} \mathrm{O}$ & indutor de resistência \\
\hline Óleo de Citronela & Citronelal, geraniol, limoneno e citronelol & $1 \mathrm{~L} / 100 \mathrm{~L} \mathrm{H}_{2} \mathrm{O}$ & inseticida \\
\hline Forth & Rotenona & $3 \mathrm{~mL} / 1 \mathrm{~L} \mathrm{H}_{2} \mathrm{O}$ & inseticida \\
\hline Pironim $^{\circledR}$ & $\begin{array}{l}\text { Azadiractina, rotenona, piretro natural, } \\
\text { extrato pirolenhoso }\end{array}$ & $600 \mathrm{~mL} / 100 \mathrm{~L} \mathrm{H}_{2} \mathrm{O}$ & inseticida \\
\hline Calda Bordalesa & Sulfato de cobre e cal hidratada & $\begin{array}{l}1 \mathrm{Kg} \mathrm{CuSO} 4+1 \mathrm{Kg} \\
\mathrm{Cal} / 10 \mathrm{~L} \mathrm{H}_{2} \mathrm{O}\end{array}$ & fungicida \\
\hline Planta Clean ${ }^{\circledR}$ & Extratos vegetais e sais minerais & $25 \mathrm{~mL} / 1 \mathrm{~L}$ de $\mathrm{H}_{2} \mathrm{O}$ & fungicida \\
\hline Calda Sulfocálcia & Enxofre + cal hidratada & $\begin{array}{l}5 \mathrm{~kg} \mathrm{~S}+2,5 \mathrm{~kg} \mathrm{de} \\
\mathrm{Cal} / 10 \mathrm{~L} \mathrm{H} 2 \mathrm{O}\end{array}$ & fungicida \\
\hline
\end{tabular}

${ }^{1}$ Informações contidas nos rótulos dos produtos; ${ }^{2}$ Concentração recomendada pelo fabricante.

Fonte: Elaboração dos autores.

Tabela 2. Plantas utilizadas para obtenção dos extratos nos tratamentos, nome popular, partes utilizadas e atividade biológica.

\begin{tabular}{llcc}
\hline \multicolumn{1}{c}{ Nome científico } & Nome popular & Partes utilizadas & Atividade \\
\hline Rosmarinus officinalis & Alecrim & folhas & repelente de insetos \\
Cymbopogon citratus & Capim Cidreira & folhas & repelente de insetos \\
Cymbopogon winterianus & Citronela & folhas & repelente de insetos \\
Laurus nobilis & Louro & folhas & repelente de insetos \\
Azadirachta indica & Nim & folhas & repelente de insetos \\
Ricinus communis & Mamona & folhas & repelente de insetos \\
Melia azedarach & Cinamomo & folhas & inseticida \\
Eucalyptus citriodora & Eucalipto & folhas & inseticida \\
Ruta graveolens & Arruda & folhas & inseticida \\
Curcuma longa & Curcuma & raiz & fungicida \\
Cinnamomum zeylanicum & Canela & folhas & fungicida e inseticida \\
Pycnoporus sanguineus & Orelha de pau & basidiocarpos & indutor de resistência \\
\hline
\end{tabular}

Fonte: Elaboração dos autores.

Para obtenção dos extratos, partes das plantas (folhas e raiz) foram coletadas na região Oeste do Paraná, no período matutino e transferidas para estufa de secagem regulada para $40{ }^{\circ} \mathrm{C}$, onde permaneceram entre 3 a 6 dias, dependendo da planta. O material seco foi moído em moinho de facas e o pó obtido, com granulometria próxima de $0,42 \mathrm{~mm}$ foi armazenado em recipientes de vidro hermeticamente fechados, em temperatura ambiente e ao abrigo da luz. Uma exsicata de cada planta foi enviada ao Herbário da Universidade Estadual do Oeste do Paraná para a identificação botânica e o registro do exemplar voucher.

Para obtenção do extrato aquoso, amostras de $10 \mathrm{~g}$ de pó foram adicionadas a $100 \mathrm{~mL}$ de água 
destilada esterilizada, permanecendo $48 \mathrm{~h} \mathrm{em}$ temperatura ambiente e ao abrigo da luz. Após esse período, fez-se a filtragem em gaze de algodão e papel filtro esterilizado sendo o filtrado conservado em recipiente hermeticamente fechado no escuro a $-10{ }^{\circ} \mathrm{C}$. Para o preparo do extrato de $P$. sanguineus foi utilizada a metodologia desenvolvida por Viecelli et al. (2010), na qual $1 \mathrm{~g}$ do pó é adicionado a $14 \mathrm{~mL}$ de água destilada esterilizada e mantido $10{ }^{\circ} \mathrm{C}$ por $24 \mathrm{~h}$. Em seguida, fez-se a esterilização a vácuo, com membrana de porosidade de $0,45 \mathrm{~mm}$ e em sequência, armazenou-se hermeticamente e no escuro em $-10^{\circ} \mathrm{C}$, por até 30 dias.

Para a obtenção do extrato alcoólico $50 \mathrm{~g}$ do pó foram adicionados em $500 \mathrm{~mL}$ de álcool etílico P.A. Após 10 dias, em temperatura ambiente e ao abrigo da luz, foi realizada a filtragem em papel filtro esterilizado, e o filtrado obtido foi transferido para um balão de vidro previamente pesado, para posterior rotaevaporação completa do solvente. Em seguida, pesou-se o balão novamente, e adicionouse água destilada esterilizada na proporção do peso do resíduo para obter uma concentração de $10 \%$, sendo em seguida filtrado e armazenado conforme descrito para o extrato aquoso.

Microrganismo utilizado. $O$ fungo utilizado foi o isolado Unioeste 22 de Metarhizium anisopliae, proveniente do banco de patógenos do Laboratório de Biotecnologia Agrícola da Unioeste (Campus Cascavel), multiplicado em meio de cultura para obtenção de esporos (Ágar 20 g, extrato de levedura $5 \mathrm{~g}$, mistura de sais $4,6 \mathrm{~g}$, glicose $10 \mathrm{~g}$ e água destilada $1000 \mathrm{~mL})$ incubado por sete dias $\left(26 \pm 1{ }^{\circ} \mathrm{C}\right.$ e $12 \mathrm{~h}$ de fotofase) (ALVES, MOINO; ALMEIDA, 1998). Após esse período, os conídios foram coletados e acondicionados em tubos de vidro esterilizados e mantidos a $-10{ }^{\circ} \mathrm{C}$ por um período não superior a 30 dias até a realização dos bioensaios.

Avaliações dos Parâmetros Biológicos. Foram avaliados os parâmetros biológicos, germinação dos conídios, unidades formadoras de colônias, crescimento vegetativo e produção de conídios no sentido de identificar prováveis efeitos dos produtos avaliados (produtos comerciais e extratos aquosos e alcoólicos) sobre $M$. anisopliae, conforme estudos desenvolvidos por Alves, Moino e Almeida (1998), Silva, Neves e Santoro (2005) e Oliveira (2009).

Para tal, foram preparadas suspensões com os conídios produzidos, em tubos de vidro com $10 \mathrm{~mL}$ de água destilada esterilizada + Tween ${ }^{\circledR} 80(0,01 \%)$, com agitação vigorosa e quantificação em câmara de Neubauer, padronizando-se na concentração de $1 \times 10^{9}$ conídios $/ \mathrm{mL}$.

A) Germinação: o meio de cultura a base de Batata, Dextrose e Ágar (BDA) + 5 mg de tetraciclina foi vertido em placas de Petri de fundo quadriculado. Após solidificação, foram inoculados $300 \mu \mathrm{L}$ da suspensão de conídios $\left(1,65 \times 10^{6}\right.$ conídios $\left./ \mathrm{mL}\right)$ no centro das placas que foram levemente agitadas para espalhar a suspensão. Em seguida, foi feita a pulverização através de um pulverizador acoplado a um compressor de ar, sob pressão constante de $0,84 \mathrm{kgf} / \mathrm{cm}^{2}$, sendo $250 \mu \mathrm{L}$ dos diferentes extratos e produtos por placa. As placas foram mantidas por $16 \mathrm{~h}$ a $26{ }^{\circ} \mathrm{C}$ e 12 horas de fotofase e então, fezse a contagem do número de conídios germinados e não-germinados nos quatro campos centrais de cada placa, em microscópio óptico, totalizando-se aproximadamente 200 conídios/placa.

B) Unidades Formadoras de Colônia (UFC): foram adotados os mesmos procedimentos do item anterior, porém, inocularam-se $100 \mu \mathrm{L}$ da suspensão $\left(1 \times 10^{3}\right.$ conídios $\left./ \mathrm{mL}\right)$ e as placas permaneceram em incubação por cinco dias, quando se fez a contagem das colônias formadas.

C) Crescimento vegetativo: o fungo foi inoculado com uma alça de platina em 3 pontos equidistantes na superfície do meio de cultura BDA e as placas foram incubadas nas mesmas condições, por 48 h, quando se fez a pulverização dos tratamentos para evitar a remoção dos conídios. As placas foram novamente incubadas nas mesmas condições, durante cinco dias. Foram feitas duas medidas perpendiculares das colônias, visando-se obter o diâmetro médio destas. 
D) Produção de conídios: após a avaliação do crescimento vegetativo, duas colônias de cada uma das placas foram recortadas e transferidas individualmente para tubos de vidro esterilizado, onde foram adicionados $10 \mathrm{~mL}$ de água destilada com Tween $80(0,01 \%)$ para agitação, até o desprendimento dos conídios. Em seguida, procedeu-se a contagem dos conídios em câmara de Neubauer.

Em todos os experimentos, para cada tratamento e também para a testemunha (meio desprovido de DFA), foram preparadas cinco placas, cada uma considerada uma repetição.

Os dados obtidos dos diferentes parâmetros biológicos foram analisados quanto à variância (teste F) e as médias comparadas pelo teste de Scott Knott, ambos com 5\% de significância, utilizando o programa Sisvar versão 4.0 (FERREIRA, 2011).

Também verificou-se a compatibilidade entre os tratamentos e o fungo, conforme o cálculo de toxicidade proposto por Rossi-Zalaf et al. (2008):

$$
\mathrm{IB}=\frac{47[\mathrm{CV}]+43[\mathrm{ESP}]+10[\mathrm{GER}]}{100}, \text { onde: }
$$

$\mathrm{IB}=$ Índice Biológico; $\mathrm{CV}=$ porcentagem do crescimento vegetativo da colônia após 7 dias, em relação à testemunha; $\mathrm{ESP}=$ porcentagem da esporulação das colônias após 7 dias, em relação à testemunha; GER= porcentagem de germinação dos conídios após $16 \mathrm{~h}$, visto que os valores de CV, ESP e GER devem ser previamente corrigidos em relação às respectivas testemunhas. Os valores do IB $(p=0,05)$ para a classificação dos produtos foram: Tóxico 0-41; Moderadamente Tóxico 42-66 e Compatível $>66$.

\section{Resultados e Discussão}

Produtos comerciais: Em geral, todos os produtos com atividade fungicida diferiram (com redução) da testemunha em relação aos parâmetros viabilidade e formação de UFC (Tabela 3).

Para o crescimento vegetativo, ocorreu diferença significativa para os tratamentos Planta Clean ${ }^{\circledR} 0,5$ CR e 2 CR, e Calda Bordalesa 0,5 CR, mostrando estímulo no crescimento.

No entanto, para a produção de conídios houve diferença significativa (redução) em relação à testemunha, exceto Planta Clean ${ }^{\circledR}$ 0,5CR e CR, e Calda Bordalesa 0,5CR e CR, os quais estimularam a esporulação. Esse resultado pode ter ocorrido pelo fato da Calda Bordalesa ser composta por cal hidratada e sulfato de cobre que apresentam atividade antifúngica.

Esse resultado divergiu dos encontrados por Wenzel et al. (2008), em relação ao efeito do cobre, contudo, os autores avaliaram o efeito do agrotóxico Cuprozed (a base de oxicloreto de cobre) no crescimento, esporulação e viabilidade do fungo Lecanicillium lecanii. Verificaram a influência do fungicida no crescimento e esporulação, no entanto a capacidade de germinação dos conídios não foi afetada. 
Tabela 3. Médias de viabilidade, unidades formadoras de colônia (UFC), diâmetro, produção de conídios, valores de "T" e compatibilidade do isolado Unioeste 22 de Metarhizium anisopliae submetido a diferentes produtos.

\begin{tabular}{|c|c|c|c|c|c|}
\hline Fungicidas & Viabilidade (\%) & UFC & Diâmetro $(\mathrm{cm})$ & $\begin{array}{c}\text { conídios } \\
\left(\times 10^{6} / \mathrm{mL}\right)\end{array}$ & $\mathrm{T} / \mathrm{C}^{2}$ \\
\hline Testemunha & $95,96 \mathrm{a}$ & $199,40 \mathrm{a}$ & $2,42 \mathrm{~b}$ & $41,83 \mathrm{~b}$ & - \\
\hline Planta Clean ${ }^{\circledR} 0,5 \mathrm{CR}^{1}$ & $74,29 \mathrm{c}$ & $144,40 \mathrm{c}$ & $2,67 \mathrm{a}$ & $62,46 \mathrm{a}$ & $124,00 / \mathrm{C}$ \\
\hline Planta Clean ${ }^{\circledR}$ CR & $70,38 \mathrm{c}$ & $151,40 \mathrm{~b}$ & $2,38 \mathrm{~b}$ & $60,02 \mathrm{a}$ & $115,25 / \mathrm{C}$ \\
\hline Planta Clean ${ }^{\circledR} 2 \mathrm{CR}$ & $77,26 \mathrm{~b}$ & $143,20 \mathrm{c}$ & $2,63 \mathrm{a}$ & $47,77 \mathrm{~b}$ & $108,23 / \mathrm{C}$ \\
\hline C. Bordalesa 0,5CR & $68,86 \mathrm{~d}$ & $149,60 \mathrm{~b}$ & $2,50 \mathrm{a}$ & $63,84 \mathrm{a}$ & 121,34 / C \\
\hline C. Bordalesa CR & $70,35 \mathrm{~d}$ & $116,40 \mathrm{~d}$ & $2,45 \mathrm{~b}$ & $59,75 \mathrm{a}$ & 116,53 / C \\
\hline C. Bordalesa 2CR & $61,24 \mathrm{~d}$ & $115,20 \mathrm{~d}$ & $2,43 \mathrm{~b}$ & $52,20 \mathrm{~b}$ & 108,23 / C \\
\hline C. Sulfocálcica 0,5CR & $60,23 \mathrm{~d}$ & $15,20 \mathrm{e}$ & $2,36 \mathrm{~b}$ & $30,92 \mathrm{c}$ & 83,89 / C \\
\hline C. Sulfocálcica CR & $52,57 \mathrm{~d}$ & $5,20 \mathrm{f}$ & $2,21 \mathrm{~b}$ & $14,61 \mathrm{~d}$ & $63,41 / \mathrm{MT}$ \\
\hline C. Sulfocálcica 2CR & $25,66 \mathrm{e}$ & $0,00 \mathrm{f}$ & $2,23 \mathrm{~b}$ & $18,17 \mathrm{~d}$ & $64,85 / \mathrm{MT}$ \\
\hline Teste F & 51.96 & 1096.07 & 2,85 & 17,04 & - \\
\hline C.V. & 8.62 & 4.61 & 8,15 & 21,95 & - \\
\hline Indutores de Resistência & Viabilidade (\%) & UFC & Diâmetro $(\mathrm{cm})$ & $\begin{array}{l}\text { Conídios } \\
\left(\times 10^{6} / \mathrm{mL}\right)\end{array}$ & $\mathrm{T} / \mathrm{C}$ \\
\hline Testemunha & $95,96 \mathrm{a}$ & $199,40 \mathrm{a}$ & $2,42 \mathrm{a}$ & $41,83 \mathrm{~b}$ & - \\
\hline Agro-mos ${ }^{\circledR} 0,5 \mathrm{CR}$ & $83,16 \mathrm{c}$ & $184,60 \mathrm{~b}$ & $3,37 \mathrm{a}$ & $37,00 \mathrm{~b}$ & 96,23 / C \\
\hline Agro-mos ${ }^{\circledR} \mathrm{CR}$ & $89,85 \mathrm{~b}$ & $181,40 \mathrm{~b}$ & $2,40 \mathrm{a}$ & $45,78 \mathrm{a}$ & $104,00 / C$ \\
\hline Agro-mos ${ }^{\circledR} 2 \mathrm{CR}$ & $75,16 \mathrm{~d}$ & $179,60 \mathrm{~b}$ & $2,41 \mathrm{a}$ & $46,81 \mathrm{a}$ & $102,76 / C$ \\
\hline Agro-fos $0,5 \mathrm{CR}$ & $85,71 \mathrm{c}$ & $179,60 \mathrm{~b}$ & $2,35 \mathrm{a}$ & $37,79 \mathrm{~b}$ & 93,61 / C \\
\hline Agro-fos CR & $82,70 \mathrm{c}$ & $178,80 \mathrm{~b}$ & $3,36 \mathrm{a}$ & $42,50 \mathrm{~b}$ & 98,33 / C \\
\hline Agro-fos 2CR & $84,91 \mathrm{c}$ & $156,40 \mathrm{~d}$ & $2,27 \mathrm{a}$ & $45,89 \mathrm{a}$ & $100,10 / C$ \\
\hline Biogermex ${ }^{\circledR} 0,5 \mathrm{CR}$ & $85,97 \mathrm{c}$ & $176,00 \mathrm{~b}$ & $2,29 \mathrm{a}$ & $38,37 \mathrm{~b}$ & 92,86 / C \\
\hline Biogermex $^{\circledR} \mathrm{CR}$ & $85,77 \mathrm{c}$ & $171,80 \mathrm{c}$ & $3,39 \mathrm{a}$ & 46,39 a & 103,23 / C \\
\hline Biogermex $^{\circledR} 2 \mathrm{CR}$ & $83,83 \mathrm{c}$ & $160.20 \mathrm{~d}$ & $2,36 \mathrm{a}$ & $40,03 \mathrm{~b}$ & $95,71 / \mathrm{C}$ \\
\hline Bion $^{\circledR} 0,5$ CR & $62,78 \mathrm{e}$ & $181,80 \mathrm{~b}$ & $2,35 \mathrm{a}$ & $47,54 \mathrm{a}$ & $101,04 / \mathrm{C}$ \\
\hline Bion $^{\circledR}$ CR & $61,24 \mathrm{e}$ & $178,80 \mathrm{a}$ & $2,40 \mathrm{a}$ & 54,44 a & 108,95 / C \\
\hline Bion $^{\circledR} 2 \mathrm{CR}$ & $60,47 \mathrm{e}$ & $170,40 \mathrm{c}$ & $2,49 \mathrm{a}$ & $40,84 \mathrm{~b}$ & $96,84 / \mathrm{C}$ \\
\hline Teste F & 72,07 & 27,31 & 1,06 & 2,37 & - \\
\hline C.V. & 3,77 & 2,61 & 5,23 & 16,40 & - \\
\hline Inseticidas & Viabilidade (\%) & UFC & $\begin{array}{l}\text { Diâmetro } \\
\text { (cm) }\end{array}$ & $\begin{array}{l}\text { Conídios } \\
\left(\times 10^{6} / \mathrm{mL}\right)\end{array}$ & $\mathrm{T} / \mathrm{C}$ \\
\hline Testemunha & $95,96 \mathrm{a}$ & $199,40 \mathrm{a}$ & $2,42 \mathrm{~b}$ & $41,83 \mathrm{~b}$ & - \\
\hline Forth $0,5 \mathrm{CR}$ & $91,90 \mathrm{a}$ & $181,40 \mathrm{~b}$ & $2,44 \mathrm{~b}$ & $41,82 \mathrm{~b}$ & 100,13 / C \\
\hline Forth CR & 91,63 a & $178,00 \mathrm{~b}$ & $2,37 \mathrm{~b}$ & $36,64 \mathrm{~b}$ & 93,24 / C \\
\hline Forth $2 \mathrm{CR}$ & $88,04 \mathrm{a}$ & $179,20 \mathrm{~b}$ & $2,34 \mathrm{~b}$ & 58,79 a & $115,05 / \mathrm{C}$ \\
\hline Oleo de Citronela 0,5 CR & $75,49 \mathrm{~b}$ & $143,60 \mathrm{c}$ & $2,41 \mathrm{~b}$ & $55,85 \mathrm{a}$ & 112,28 / C \\
\hline Oleo de Citronela CR & $77,41 \mathrm{~b}$ & $145,00 \mathrm{c}$ & $2,40 \mathrm{~b}$ & $51,55 \mathrm{a}$ & 107,87 / C \\
\hline Oleo de Citronela 2 CR & $70,91 \mathrm{~b}$ & $141,40 \mathrm{c}$ & $2,45 \mathrm{~b}$ & $43,29 \mathrm{~b}$ & 99,66 / C \\
\hline Pironim $^{\circledR} 0,5 \mathrm{CR}$ & $73,09 \mathrm{~b}$ & $140,40 \mathrm{c}$ & $2,80 \mathrm{a}$ & $55,84 \mathrm{a}$ & 119,39 / C \\
\hline Pironim ${ }^{\circledR}$ CR & $73,37 \mathrm{~b}$ & $143,00 \mathrm{c}$ & $2,49 \mathrm{~b}$ & $61,84 \mathrm{a}$ & 119,76 / C \\
\hline Pironim $^{\circledR} 2 \mathrm{CR}$ & $68,90 \mathrm{~b}$ & $149,20 \mathrm{c}$ & $2,56 \mathrm{~b}$ & $55,34 \mathrm{a}$ & 113,79 / C \\
\hline CV $(\%)$ & 5.23 & 3,43 & 5,11 & 21,44 & - \\
\hline Fator F & 28.58 & 79.86 & 5,33 & 3,21 & - \\
\hline
\end{tabular}

Médias seguidas de mesma letra na coluna, não diferem entre si pelo Teste de Scott Knott a 5\% de significância.

${ }^{1}$ Concentrações dos produtos: $0,5 \mathrm{CR}=$ Metade da concentração recomendada; $\mathrm{CR}=$ Concentração recomendada; $2 \mathrm{CR}=\mathrm{Dobro}$ da concentração recomendada.

C.V. $=$ Coeficiente de variação

${ }^{2}$ Valores de T, segundo Rossi-Zalaf et al. (2008) entre 0 e 41 = tóxico; entre 42 e $66=$ Moderadamente tóxico; maiores que $66=$ compatível.

Fonte: Elaboração dos autores. 
O produto Calda Sulfocálcica diferiu da testemunha e apresentou redução significativa nas UFC, produção de conídios e viabilidade, nas três concentrações testadas, sendo que na CR e no 2 CR apresentaram redução de $67 \%$ na produção de conídios (Tabela 3). O efeito negativo da Calda Sulfocálcica pode ser atribuído à presença de polissulfetos de cálcio que proporciona ação fungicida (ABREU JUNIOR, 1998; AZEVEDO, 2003). Nesse sentido, estudos realizados por SosaGomez et al. (2003) demonstram que o produto Kumulus DF, à base de enxofre, inibiu a germinação de conídios de Nomuraea rileyi (fungo da mesma família de $M$. anisopliae) em mais de 90\%, corroborando com dados deste trabalho. Também, Formentini (2009) observou redução nos parâmetros UFC, diâmetro e produção de conídios quando avaliou a compatibilidade do produto Stubble-Aid, que contém enxofre na sua composição, com o fungo $M$. anisopliae.

Para os produtos indutores de resistência, observou-se que os tratamentos para os parâmetros viabilidade e UFC também diferiram da testemunha (redução). Dentre os produtos, verificou-se que o Bion $^{\circledR}$ em todas as concentrações e o Agro-mos ${ }^{\circledR}$ no $2 \mathrm{CR}$ apresentaram maiores reduções em relação à germinação (Tabela 3). Os valores de UFC, em média diminuíram 18\% para o produtos Agro-fos e $\operatorname{Bion}^{\circledR}(2 \mathrm{CR})$ e Biogermex ${ }^{\circledR}$ (CR e 2CR) (Tabela 3).

O produto Biogermex ${ }^{\circledR}$ possui em sua composição bioflavonóides, que segundo Tsuchiya et al. (1996) têm capacidade de se ligar com proteínas extracelulares e paredes celulares de bactérias e fungos, inativando-as e rompendo-as. Diante do exposto, é provável que a redução das UFCs esteja relacionada ao impedimento do processo de germinação e ou a ação dos referidos metabólitos sobre a membrana logo após a germinação, destruindo-a (SILVA, 2010).

Em relação ao diâmetro, não houve diferença significativa entre os tratamentos. Entretanto para a conidiogênese, os produtos Agro-mos ${ }^{\circledR}$ (CR e 2 CR),
Agro-fos (2 CR), Biogermex ${ }^{\circledR}(\mathrm{CR})$ e $\operatorname{Bion}^{\circledR}(0,5$ CR e CR), diferiram da testemunha, estimulando a produção. Porém, apesar do estímulo provocado pelo produto Bion $^{\circledR}$ na produção de conídios, o mesmo reduziu a viabilidade em 36\% (Tabela 3 ).

Ressalta-se que o Bion $^{\circledR}$ é composto por acibenzolar-S-methyl, um análogo do ácido salicílico, que segundo Resende et al. (2002), age diretamente sobre a planta e não sobre o patógeno, ativando mecanismos de defesa da planta como aumento da atividade de enzimas relacionadas a vias secundária do metabolismo e síntese de fitoalexinas.

Estudos sobre o potencial de controle de acibenzolar-S-methyl têm sido realizados com sucesso em diversos patossistemas como oídio em trigo (GÖRLACH et al., 1996); míldio em tabaco (FRIEDRICH et al., 1996) míldio em Arabidopsis (LAWTON et al., 1996); ferrugem do feijão-vagem (SIGRIEST et al., 1997); pinta preta do tomateiro (TÖFOLI, 2002) e cancro da haste em melão rendilhado (RIZZO; FERREIRA; BRAZ., 2003).

Nos produtos com características inseticidas, observou-se que Óleo de Citronela e Pironim ${ }^{\circledR}$, em todas as concentrações testadas, diferiram (redução) da testemunha para o parâmetro viabilidade. Entre as concentrações dos produtos Óleo de Citronela e Pironim ${ }^{\circledR}$ houve redução da viabilidade em média de 22 e $25 \%$, respectivamente.

Analisando-se o efeito sobre a viabilidade do fungo $M$. anisopliae, resultados semelhantes foram encontrados por Hirose et al. (2001) que relataram redução significativa da germinação do M. anisopliae CB 38 quando aplicado óleo de nim (2\%). Da mesma forma, Formentini (2009), que utilizou o produto Dalneem ${ }^{\circledR}$, a base de óleo de nim, observando reduções de aproximadamente 20 e $15 \%$, na $0,5 \mathrm{CR}$ e $\mathrm{CR}$, respectivamente

Para UFC, os mesmos produtos causaram redução média de $28 \%$, sendo significativo.

Em relação ao diâmetro, somente o produto Pironim $^{\circledR}$ a 0,5 CR diferiu da testemunha com 
um aumento de $15 \%$. Em relação à produção de conídios, a testemunha não diferiu dos tratamentos Forth (0,5 e CR) e Óleo de Citronela (2 CR), já os outros produtos estimularam a produção de conídios, apesar da influência dos produtos na viabilidade e UFC (Tabela 3).

Esse aumento na produção de conídios, estimulado por alguns produtos, pode ter acontecido devido à degradação e metabolização dos princípios tóxicos pelo fungo (ALVES, 1998).

Ainda, Moino e Alves (1998) argumentam que o microrganismo, num mecanismo de resistência fisiológica, pode metabolizar os componentes do ingrediente ativo, utilizando as moléculas resultantes desse processo, liberadas no meio de cultura, como nutrientes secundários, promovendo seu crescimento vegetativo e a conidiogênese. Com relação à compatibilidade, todos os produtos testados com características de indutores de resistência e inseticidas foram compatíveis com o fungo $M$. anisopliae, e dentre os fungicidas, apenas o Calda Sulfocálcica na CR e 2 CR, foram classificados como moderadamente tóxicos (Tabela 3 ).

Extratos aquosos. Observou-se que todos os extratos afetaram de alguma maneira o fungo, reduzindo a viabilidade, a UFC, o diâmetro ou a produção de conídios. Para a viabilidade, verificouse que apenas o extrato de cinamomo não diferiu da testemunha, enquanto que os extratos de capim cidreira e citronela apresentaram maior redução sobre o fungo M. anisopliae (Tabela 4).

Rozwalka et al. (2008), utilizando extrato de capim cidreira a 10\% misturado em BDA, observaram redução do crescimento micelial, embora tenha trabalhado com o fungo Coletrotricum gloeosporioides (Melanconiales), corroborando com o resultado deste trabalho. Da mesma forma, o efeito fungitóxico do óleo essencial de capim cidreira foi comprovado para Glomerella cingulata (Diaportales), apresentando inibição de 100\% do crescimento micelial.

A ação negativa do capim cidreira sobre os parâmetros avaliados de $M$. anisopliae pode ser explicada pela grande quantidade do composto saponina, encontrado no extrato aquoso das folhas. A saponina tem a capacidade de formar complexos com proteínas e fosfolipídeos de membranas, alterando a sua permeabilidade, ou causando sua destruição (SIMÕES et al., 2002).

Os valores médios de UFC obtidos com os extratos de canela, louro e orelha de pau não diferiram da testemunha. Já os extratos de eucalipto, capim cidreira, arruda, mamona, cúrcuma, citronela e alecrim reduziram de 20 a $35 \%$ as UFCs em relação à testemunha (Tabela 4).

No diâmetro, os extratos de louro, nim, mamona, eucalipto, cúrcuma e orelha de pau não provocaram alterações significativas em relação à testemunha, ao contrário dos extratos de capim cidreira, arruda, cinamomo, canela, citronela e alecrim, com os quais houve redução entre 1,8 a 7,6 \% (Tabela 4).

$\mathrm{Na}$ produção de conídios, observou-se que os extratos capim cidreira, arruda, canela, alecrim e orelha de pau diferiram, significativamente, da testemunha, com redução na produção entre 24 a $39 \%$. No entanto, com o extrato de eucalipto obteve-se a maior produção de conídios, ocorrendo um estímulo, assim como o crescimento vegetativo aumentou (Tabela 4).

Estudos realizados por Formentini (2009), avaliando a atividade antimicrobiana do extrato de eucalipto sobre $M$. anisopliae mostraram redução no crescimento vegetativo, divergindo deste trabalho, provavelmente por ter sido aqui empregado material vegetal seco para o extrato, além de outros fatores relacionados como estado nutricional da planta, época de coleta, entre outros.

A redução causada pelo extrato de eucalipto na viabilidade e UFC pode ser explicada pela presença de taninos, que inibem as enzimas do fungo, ou se unem aos substratos dessas enzimas, ou ainda os taninos agiram sobre a membrana celular dos fungos, alterando seu metabolismo (SIMÕES et al., 2002). 
Estudos realizados por Pedroso et al. (2009), analisando o crescimento micelial do fungo Alternaria solani (Moniliales), comprovaram que o extrato de arruda a $10 \%$ inibiu o crescimento vegetativo do fungo. Também Celoto et al. (2008) verificaram que o extrato aquoso de arruda $20 \%$ inibiu mais de $90 \%$ da germinação de esporos do fungo C. gloeosporioides.

A mamona em geral apresentou um estímulo no crescimento vegetativo, mas reduziu as UFC em cerca de $22 \%$. Isto pode ter ocorrido pela presença de ricina, a qual é muito tóxica, inibindo os ribossomos, interrompendo a síntese protéica (LORD; ROBERTS; ROBERTUS, 1994). Este composto pode ter interferido no metabolismo do fungo, reduzindo sua viabilidade e as unidades formadoras de colônias. A possível explicação da redução das UFCs e não do crescimento vegetativo, seria devido à aplicação do extrato para avaliar a UFC ser no próprio dia que foi inoculado o fungo, já no crescimento vegetativo, o extrato foi aplicado 48 horas após a inoculação do fungo, permitindo a germinação e o desenvolvimento do fungo.

O extrato de cinamomo reduziu a UFC em 17\%, contrastando com o estudo de Milanesi et al. (2009), que avaliaram o efeito dos extratos de cinamomo (Melia azeradach) sobre o crescimento micelial de C. gloeosporioides, concluindo que o mesmo não se mostrou efetivo no controle do fungo, e ainda observaram estímulo no crescimento micelial do fitopatógeno.

A cúrcuma apresenta atividade fungicida, no entanto apenas as UFC foram prejudicadas. A cúrcuma é conhecida pelo seu emprego na medicina e na alimentação devido à presença de corantes, substâncias antioxidantes e antimicrobianas (CECÍLIO FILHO et al., 2000), sendo a curcumina o principal composto do rizoma da cúrcuma (COUTINHO et al., 2004).

$\mathrm{O}$ efeito inibitório no crescimento micelial causado pelo extrato do rizoma de cúrcuma foi evidenciado para Fusarium oxysporum e Rhizoctonia solani, que pertencem à mesma classe Hyphomycetes, alcançando $60 \%$ de redução na concentração de 1\% em meio BDA (AMARAL; BARA, 2005). Contudo, torna-se difícil a comparação entre os trabalhos pela diferença no método adotado pelos autores citados, os quais incorporaram os extratos no meio BDA.

O extrato das folhas de canela apresenta atividade inseticida e fungicida, no entanto apresentou maior ação sobre a produção de conídio. Isso pode ter ocorrido devido à presença de tanino, que tal como citado para o extrato de eucalipto, possui a propriedade de inibir enzimas dos fungos e até mesmo de se ligar ao substratos dessas enzimas (SIMÕES et al., 2002).

O extrato de citronela foi prejudicial para a germinação e UFC. Vale ressaltar que a maioria dos trabalhos encontrados são com o óleo de citronela, o que dificulta a discussão, já que a forma de extração é feita mediante destilação por arraste com vapor de água.

Ainda assim, Lima et al. (2010) observaram que nas concentrações superiores a 1500 ppm, o óleo citronela reduziu (100\%) a germinação de Colletotrichum gossypii (Melanconiales), fungo responsável pela ramulose, principal doença que ataca o algodoeiro. 


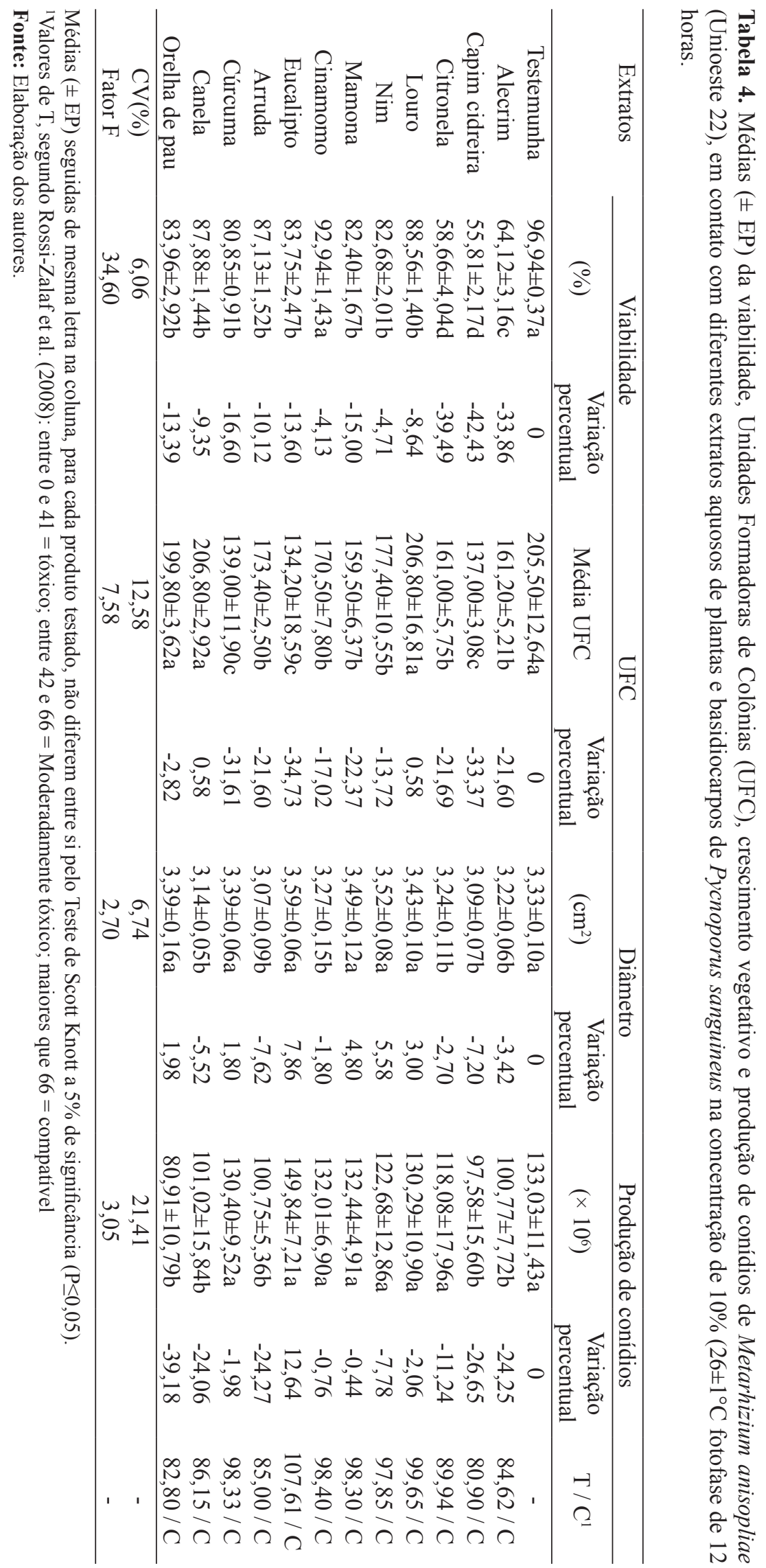


$\mathrm{O}$ extrato de alecrim influenciou a atividade fúngica nos parâmetros das UFC e produção de conídios, reduzindo-os. Provavelmente esse resultado ocorreu pela presença do terpeno, que possui característica lipofílica, compartilhando a fase aquosa das estruturas da membrana, causando sua expansão e desordem na estrutura da mesma, além de inibição de enzimas ali embebidas, podendo ser esses efeitos os responsáveis pela atividade antifúngica desse extrato (SIKKEMA; BORT; POOLMAN, 1995).

O extrato de orelha de pau é usado como indutor de resistência, contudo, de acordo com Viecelli et al. (2009), o extrato de filtrado de cultura de $P$. sanguineus não interferiu na produção de conídios, viabilidade e crescimento do fungo Pseudocercospora griseola, discordando dos resultados encontrados no presente trabalho, os quais diferiram da testemunha para viabilidade e produção de conídios (Tabela 4).

Em relação à toxicidade, todos os extratos vegetais aquosos e basidiocarpos de $P$. sanguineus mostraram-se compatíveis ao fungo (Tabela 4). Formentini (2009) encontrou resultados semelhantes, quando estudou os extratos de alecrim, eucalipto, capim-limão e cúrcuma sobre M. anisopliae, sendo o alecrim o que mais afetou o fungo.

Extratos alcoólicos. Dentre os parâmetros testados, somente UFC, não diferiu da testemunha. Os demais parâmetros sofreram redução pelos extratos vegetais alcoólicos (Tabela 5).

Em relação à viabilidade dos conídios, verificouse que houve redução entre 53 e $84 \%$ dos tratamentos com sua respectiva testemunha (Tabela 5).

$\mathrm{O}$ número de UFC formadas na presença dos extratos foi reduzido em relação a sua respectiva testemunha, porém, não foi significativo.

O crescimento vegetativo do fungo em contato com arruda, mamona, cinamomo e nim também foi reduzido entre 5 e $11 \%$, assim como ocorreu em relação à conidiogênese, cuja produção do fungo decresceu 35\%, sendo que ambos diferiram da testemunha (Tabela 5).

O extrato alcoólico de citronela estimulou o crescimento vegetativo em 5,3\%, assim como também estimulou a produção de conídios em $12,7 \%$, entretanto sua viabilidade foi reduzida em torno de $75 \%$.

O extrato alcoólico de alecrim também provocou redução na produção de conídios, em $27 \%$, diferindo de sua testemunha. Neste caso, os terpenos que compõem o alecrim, podem ser os responsáveis por parte da inibição do crescimento do fungo. Estudos semelhantes, mas com o óleo essencial, também demonstraram o potencial antimicrobiano deste extrato sobre fungos fitopatogênicos nos estudos realizados por Pereira et al. (2006) e Itako et al. (2008), eles avaliaram a inibição do crescimento micelial, produção de conídios e germinação dos conídios.

Quanto ao eucalipto, sua ação reduziu em $72 \%$ a viabilidade dos conídios e cerca de $23 \%$ na quantidade de UFC. O extrato desta planta não afetou o crescimento vegetativo das colônias, e a conidiogênese teve uma redução percentual de $11 \%$, não diferindo da testemunha (Tabela 5).

Em relação aos dados obtidos com o fungo produzido em contato com o extrato de capimcidreira, verificou-se que a germinação dos conídios foi afetada em $75 \%$. O número de UFC reduzido foi de $28 \%$, quanto ao crescimento vegetativo, não houve diferença estatística significativa, não interferindo também na produção de conídios, porém apenas $25 \%$ dos conídios produzidos são viáveis (Tabela 5).

Já os dados obtidos com o fungo produzido em contato com o extrato de arruda verificou-se que a germinação dos conídios foi afetada em $76 \%$, o número de UFC produzido foi reduzido em $28 \% \mathrm{em}$ relação à testemunha, sendo significativo (Tabela 5). 


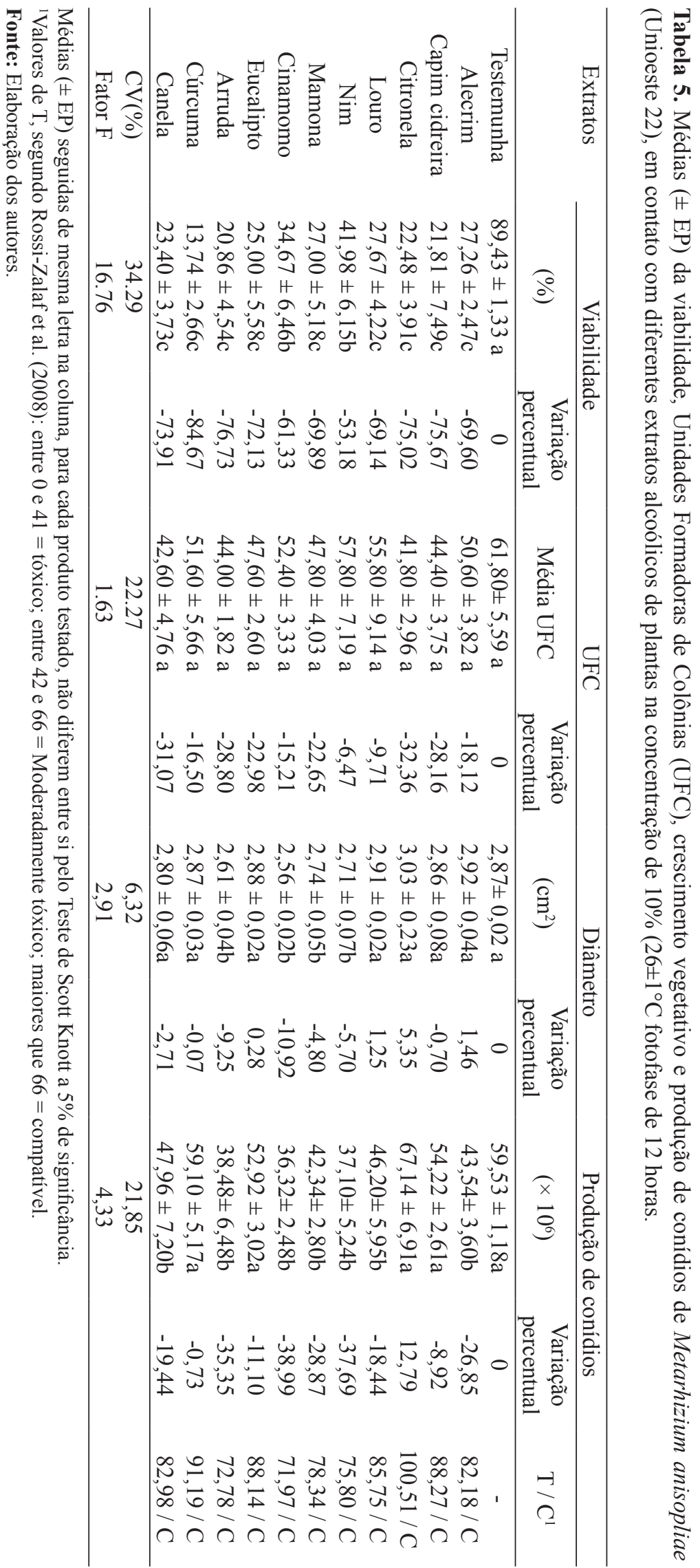


Quanto ao crescimento vegetativo, foram obtidas colônias em torno de $9 \%$ menores que a testemunha, diferindo significativamente. Além disso, observouse diminuição de $35 \%$ na produção de conídios do tratamento com arruda em relação ao controle (Tabela 5).

$\mathrm{O}$ efeito inibidor e crescimento micelial causado pelo extrato fresco de folhas de arruda também foi verificado por Salvadori et al. (2003), trabalhando com o fungo Colletotrichum gloeosporioides, obtendo até $23 \%$ de inibição.

Em relação ao extrato de mamona, verificou-se redução de $69 \%$ sobre a germinação, o número de UFC foi reduzido em torno de $22 \%$, e a conidiogênese sofre uma redução percentual significativa de $28 \%$ (Tabela 5).

O extrato de cúrcuma foi considerado prejudicial somente para o parâmetro viabilidade, sofrendo uma diminuição em torno de $84 \%$. O desenvolvimento das UFC que tiveram contato com este extrato não diferiram significativamente da testemunha (Tabela 5).

Outros estudos relacionados à atividade da cúrcuma revelam sua ação bactericida e fungicida para fungos fitopatogênicos (AMARAL; BARA, 2005; BALBI-PEÑA et al., 2006). Neste sentido, Cecílio Filho et al. (2000) fez uma revisão sobre o potencial da cúrcuma, destacando sua atividade antimicrobiana, atribuída à curcumina e aos óleos essenciais da planta. Assim como para os demais extratos vegetais aqui estudados, desconhecemse relatos sobre o efeito da cúrcuma sobre fungos entomopatogênicos.

O extrato alcoólico de canela reduziu em 74\% a viabilidade do fungo, diferindo da testemunha, já as UFCs, sofreram redução percentual de 31\%, porém não diferiram da respectiva testemunha, já a produção de conídios diferiu da testemunha, sofrendo uma redução percentual de 20\% (Tabela 5).

A canela possui com constituinte principal o cinamaldeído, o qual pode ter interferindo consideravelmente na viabilidade do fungo.
A atividade fungitóxica do extrato alcoólico de canela sobre os fungos Aspergillus ochraceus, Penicillium roqueforti e Rhizopus stolonifer, foi verificada por Araujo et al. (2009), causando total inibição o crescimento micelial nas concentrações de 10,20 e $25 \%$.

Observou-se que o extrato de cinamomo interferiu em $61 \%$ da viabilidade do fungo, o número de UFC reduzidas foram de $15 \%$, além disso, o diâmetro foi reduzido em torno de $11 \%$, reduzindo assim a produção de conídios em 39\%, sendo todos significativos (tabela 5).

O extrato de louro causou redução na viabilidade em torno de $69 \%$, também diferindo da testemunha, como todos os extratos aqui citados, mas sua redução percentual na produção de conídios não foi tão expressiva, comparando-se aos outros extratos.

O extrato de nim reduziu em 53\% a germinação do fungo, e 37\% a produção de conídios, sem afetar outros parâmetros. A ação negativa do nim sobre $M$. anisopliae tem sido demonstrada em diversos trabalhos, contudo, ressalta-se que em todos eles avaliou-se o óleo dos frutos e sementes de nim, sendo que tanto nas folhas, como nos frutos encontra-se azadiractina, o qual pode ter causado as reduções nos parâmetros. Hirose et al. (2001) obtiveram menor diâmetro das colônias $(36,8 \%)$, inibição da conidiogênese $(54,3 \%)$ e da germinação dos conídios (17,2\%), e, teste com óleo de nim, corroborando com os dados deste trabalho.

Dentre os extratos utilizados, aquoso e alcoólico, a maior alteração foi causada pelos extratos alcoólicos reduzindo a viabilidade do fungo, variando entre 50 e $80 \%$. É provável que este efeito esteja associado à solubilidade de certos compostos presentes nos extratos, nos respectivos solventes que apresentam diferentes polaridades (água e álcool). Desta forma, é possível que nos extratos alcoólicos existam compostos de ação tóxica, ausentes nos extratos aquosos.

Apesar dos extratos vegetais terem interferido na germinação e produção de conídios, todos os 
extratos apresentaram valores de toxicidade bem acima do mínimo para que possam ser considerados compatíveis. Contudo, a utilização desses extratos deve ser criteriosa, principalmente aqueles que causaram maior impacto sobre a viabilidade dos conídios, como é o caso do extrato alcoólico de cúrcuma (redução de $84 \%$ na viabilidade dos conídios). Nesse sentido, a germinação é um fator muito importante no processo de infecção, uma vez que esta inicia-se a partir da adesão dos conídios no tegumento do inseto (ALVES, 1998; NEVES et al., 2001).

Assim, conclui-se que os produtos aqui avaliados, exceto a Calda Sulfocálcica, podem ser utilizados, recomendando-se aplica-los após a aplicação do fungo $M$. anisopliae, no mínimo $48 \mathrm{~h}$, tempo necessário para a germinação dos conídios e invasão do hospedeiro pelo fungo (TAMAI et al., 2002), de forma a se estabelecer a seletividade ecológica do produto através do espaço e tempo, respectivamente (YAMAMOTO et al., 1992).

\section{Agradecimentos}

Ao CNPq, CAPES e Parque Tecnológico Itaipu (PTI) pelo suporte financeiro para o desenvolvimento da pesquisa.

\section{Referências}

ABREU JUNIOR, H. Práticas alternativas de controle de pragas e doenças na agricultura. Campinas: EMOPI, 1998. 115 p. (Coletânia de Receitas).

ALVES, S. B. Fungos entomopatogênicos. In: Controle microbiano de insetos. 2. ed. Piracicaba: FEALQ, 1998. p. 289-381.

ALVES, S. B.; LEUCONA, R. E. Epizootiologia aplicada ao controle microbiano de insetos. In: ALVES, S. B. Controle microbiano de insetos. 2. ed. Piracicaba: FEALQ, 1998. p. 97-100.

ALVES, S. B.; MOINO JUNIOR, A.; ALMEIDA, J. E. M. Produtos fitossanitários e entomopatógenos. In: ALVES, S. B. (Ed.). Controle microbiano de insetos. 2. ed. Piracicaba: FEALQ, 1998. cap. 8, p. 217-238.
ALVES, S. B.; SILVEIRA, C. A.; LOPES, R. B.; TAMAI, M. A.; RAMOS, E. Q.; SALVO, S. Eficácia de Beauveria bassiana, Imidacloprid e Thiacloprid no controle de Bemisia tabaci e na incidência do BGMV. Manejo Integrado de Plagas, Costa Rica, v. 61, dec. p. 31-36, 2001.

AMARAL, M. F. Z. J.; BARA, M. T. F. Avaliação da atividade antifúngica de extratos de plantas sobre o crescimento de fitopatógenos. Revista Eletrônica de Farmácia, Goiás, v. 2, n. 2, p. 5-8, 2005.

ARAUJO, R. de C. Z.; CHALFOUN, S. M.; ANGELICO, C. L.; ARAUJO, J. B. S.; PEREIRA, M. C. Avaliação in vitro da atividade fungitóxica de extratos de condimentos na inibição de fungos isolados de pães artesanais. Ciencia e Agrotecnologia, Lavras, v. 33, n. 2, p. 545-551, mar./ apr. 2009.

AZEVEDO, J. L. Controle microbiano de insetospragas e seu melhoramento genético. In: MELO, I. S.; AZEVEDO, J. L. (Ed.). Controle biológico. Jaguariúna: Embrapa-CNPMA, 1998. v. 1, cap. 2, p. 69-96.

AZEVEDO, L. A. S. Fungicidas protetores. São Paulo: Syngenta, 2003. 320 p.

BALBI-PEÑA, M. I.; BECKER, A.; STANGARLIN, J. R.; FRANZENER, G.; LOPES M. C.; SCHWANESTRADA, K. R. F. Controle de Alternaria Solani em tomateiro por extratos de Cúrcuma longa e curcumina II. Avaliação in vivo. Fitopatologia Brasileira, Brasília, v. 31, n. 3, p. 401-404, 2006.

CECÍLIO FILHO, A. B.; SOUZA, R. J.; BRAZ, L. T.; TAVARES, M. Cúrcuma: planta medicinal, condimentar e de outros usos potenciais. Ciência Rural, Santa Maria, v. 30 , n. 1 , p. $171-175,2000$.

CELOTO, M. I. B.; PAPA, M. F. S.; SACRAMENTO, L. V. S.; CELOTO, F. J. Atividade fungitóxica de extratos de plantas a Colletotrichum gloeosporioides. Acta Scientiarum, Maringá, v. 30, n. 1, p. 1-5, 2008.

COUTINHO, H. D. M.; BEZERRA, D. A. C.; LÔBO, K.; BARBOSA, I. J. F. Atividade antimicrobiana de produtos naturais. Revista Conceitos, Recife, v. 77, n. 6, p. 77-85, jul. 2004.

DANTAS, S. A. F.; OLIVEIRA, S. M. A.; BEZERRA NETO, E.; COELHO, R. S. B.; SILVA, R. L. X. da. Indutores de resistência na proteção do mamão contra podridões pós-colheita. Summa Phytopathologica, Recife, v. 30, n. 3, p. 314-319, 2004.

FARIA, M. R. de; MAGALHÃES, B. P. O uso de fungos entomopatogênicos no Brasil. Biotecnologia, Ciência \& Desenvolvimento, Brasília, v. 4, n. 22, p. 18-21, 2001. 
FERREIRA, D. F. SISVAR: a computer statistical analysis system. Ciência e Agrotecnologia, Lavras, v. 35, n. 6, p. 1039-1042, 2011.

FORMENTINI, M. A. Efeito in vitro de produtos fitossanitários naturais sobre Beauveria bassiana (Bals.) Vuil. e Metarhizium anisopliae (Metsch.) Sorokin. 2009. Monografia (Conclusão do Curso de Ciências Biológicas) - Universidade Estadual do Oeste do Paraná, Cascavel.

FRIEDRICH, L.; LAWTON, K.; RUESS, W.; MASNER, P.; SPECKER, N.; RELLA, M.; GUT, M.; MEIER, B.; DINCHER, S.; STAUB, T.; UKNES, S.; METRAUX, J. P.; KESSMANN, H.; RYALS, J. A. Benzothiadiazole derivate induces sistemic acquired resistance in tobacco. Plant Journal, Fribourg, v. 10, n. 1, p. 61-70, 1996.

FURLONG, M. J.; PELL, J. K. The influence of environmental factors on the persistence of Zoophthora radicans conidia. Jounal of Invertebrate Pathology, Malaysia, South-Eastern Asia, v. 69, n. 3, p. 223-233, 1997.

GÖRLACH, J.; VOLRATH, S.; KNAUF-BEITER, G.; HENGY, G.; BECKHOVE, U.; KOGEL, K. G.; OOTENDORP, M.; STAUB, T.; WARDE, E.; KESSMANN, J.; RYALS, J. Benzothiadiazole, a novel class of inducers of sistemic acquired resistance, activates gene expression and disease in wheat. The Plant Cell, Rockville, v. 8, n. 4, p. 629-643, 1996.

HIROSE, E.; NEVES, P. M. O. J.; ZEQUI, J. A. C.; MARTINS, L. H.; PERALTA, C. H.; MOINO JUNIOR, A. Effect of biofertilizers and neem oil on the enthomopatogenic fungi Beauveria bassiana (Bals.) Vuill. and Metarhizium anisopliae (Metsch.) Sorok. Tecapar, Brazilian Archives of Biology and Technology, Curitiba, v. 44, n. 4, p. 419-423, 2001.

ITAKO, A. T.; SCHAN-ESTRADA, K. R. F.; TOLENTINO JÚNIOR, J. B.; STANGARLIN, J. R.; CRUZ, M. E. da. Atividade antifúngica e proteção do tomateiro por extratos de plantas medicinais. Tropical Plant Pathology, Brasília, v. 33, n. 3, p. 241-244, 2008.

LAWTON, K. A.; FRIEDRICH, L.; HUNT, M.; WEYMAN, K.; DELANEY, T.; KESSMANN, H.; STAUB, T.; RYALS, J. Benzothiadiazole induces disease resistance in Arabidopsis by activation of the sistemic acquired resistance signal transduction pathway. Plant Journal, Research Triangle Park, v. 10, n. 1, p. 71-82, 1996.

LIMA, W. G.; MELO FILHO, P. A.; CÂMARA, M. P. S.; SANTOS, R. C. dos; CÂMARA, C. A. G. da; SILVA, A. M. da; SILVA, A. M. F. da; GARCIA, A. de L.; BEZERRA, C.S. Efeito de óleos vegetais no controle de Colletotrichum gossypii var. cephalosporioides. 2010. Disponível em: <http://www.infobibos.com/ Artigos/2010_3/OleosVegetais/index.htm>. Acesso em: 02 jun. 2011.
LORD, M. J.; ROBERTS, L. M.; ROBERTUS, J. D. Ricin: structure, mode of action and some current applications. Jounal Faseb, Reino Unido, v. 8, p. 201208, 1994.

MARQUES, R. P.; MONTEIRO, A. C.; PEREIRA, G. T. Crescimento, esporulação e viabilidade de fungos entomopatogênicos em meios contendo diferentes concentrações de óleo de Nim (Azadirachta indica). Ciência Rural, Santa Maria, v. 34, n. 6, p. 1675-1680, 2004.

MEDEIROS, M. B.; ALVES, S. B.; LOPES, R. B.; BARBOSA, A. da S.; GARCIA, M. O.; BERZAGHI, M. Associação de biofertilizante líquido e fungos entomopatogênicos no controle do pulgão Aphis sp. em aceroleira (Malpighia glabra 1.). Resumos. Revista Brasileira de Agroecologia, Manaus, v. 2, n. 2, p. 821824, 2007.

MERTZ, M. R.; ALVES, L. F. A.; MARCOMINI, A. M.; OLIVEIRA, D. G. P.; SANTOS, J. C. dos. Efeito de produtos fitossanitários naturais sobre Beauveria basiana (Bals.) Vuill. in vitro. Biossay, Lavras, v. 5, n. 3, p. 1-10, 2010 .

MILANESI, P. M.; BLUME, E.; MUNIZ, M. F. B.; BRAND, S. C.; JUNGES, E.; MANZONI, C. G.; EBER, M. N. D. Ação fungitóxica de extratos vegetais sobre o crescimento micelial de Colletotrichum gloeosporioides. Revista da FZVA, Uruguaiana, v. 16, n. 1, p. 1-13, 2009.

MOINO JUNIOR, A.; ALVES, S. B. Efeito de imidacloprid e fipronil sobre Beauveria bassiana (Bals.) Vuill. e Metarhizium anisopliae (Metsch.) Sorok. e no comportamento de limpeza de Heterotermes tenuis (Hagen). Anais Sociedade Entomologia Brasileira, Londrina, v. 27, n. 4, p. 611-619, 1998.

NEVES, P. M. O. J.; HIROSE, E.; TCHUJO, P. T.; MOINO JUNIOR, A. Compatibility of entomopathogenic fungi with neonicotinoid insecticides. Neotropical Entomology, Londrina, v. 30, n. 2, p. 263-268, 2001.

OLIVEIRA, D. G. P. Proposta de um protocolo para avaliação da viabilidade de conídios de fungos entomopatogenicos e determinação da proteção ao calor conferida a Beauveria bassiana e Metarhizium anisopliae pela formulação em óleo emocionável. 2009. Dissertação (Mestrado em Ciências) - Escola Superior de Agricultura Luiz de Queiroz, Piracicaba.

PEDROSO, D. C.; JUNGES, E.; MENEZES, V.; MULLER, J.; GIRARDI, L. B.; TUNES, L. M. de; MUNIZ, M. F. B.; DILL, A. Crescimento micelial de Alternaria solani na presença de extratos vegetais. Revista Brasileira de Agroecologia, Curitiba, v. 4, n. 2, p. 4256-4259, 2009. 
PEREIRA, M. C.; VILELA, G. R.; COSTA, L. M. A. S.; SILVA, R. F. da; FERNANDES, A. F.; FONSECA, E. W. N. da; PICCOLI, R. H. Inibição do desenvolvimento fúngico através da utilização de óleos essenciais de condimentos. Ciência e Agrotecnologia, Lavras, v. 30, n. 4, p. 731-738, 2006.

RESENDE, M. L. V.; NOJOSA, G. B. A.; CAVALCANTI, L. S.; AGUILAR, M. A. G.; SILVA, L. H. C. P.; PEREZ, J. O.; ANDRADE, G. C. G.; CARVALHO, G. A.; CASTRO, R. M. Induction of resistance in cocoa against Crinipellis perniciosa and Verticillium dahliae by acibenzolar-S-methyl (ASM). Plant Pathology, Fortaleza, v. 51, n. 5, p. 621-628. 2002.

RIZZO, A. A. N.; FERREIRA, M. R.; BRAZ, L. T. Ação de acybenzolar-S-methyl (BTH) isolado e em combinação com fungicidas no controle do cancro da haste em melão rendilhado. Horticultura Brasileira, Brasília, v. 21, n. 2, p. 238-240, 2003.

ROSSI-ZALAF, L. S.; ALVES, S. B.; LOPES, R. B.; SILVERIRA NETO, S.; TANZINI, M. R. Interação de microrganismos com outros agentes de controle de pragas e doenças, In: ALVES, S. B.; LOPES, R. B. (Ed.). Controle microbiano de pragas na América Latina: avanços e desafios. Piracicaba: FEALQ, 2008. p. 279-302.

ROZWALKA, L. C.; LIMA, M. L. R. Z. da C.; MIO, L. L. M.de; NAKASHIMA, T. Extratos, decoctos e óleos essenciais de plantas medicinais e aromáticas na inibição de Glomerella cingulata e Colletotrichum gloeosporioidesde frutos de goiaba. Ciência Rural, Santa Maria, v. 38, n. 2, p. 301-307, 2008.

SALVADORI, R. K.; POVH, F. P.; SCHWWANESTRADA, K. R. F.; STANGARLIN, J. R. Atividade antifúngica dos extratos brutos de Corymbia citriodora, Cymbopogon citratus, Ruta graveolens e Curcuma longa. Fitopatologia Brasileira, Brasília, v. 28, p. 360361, 2003. Suplemento.

SIGRIEST, J.; GLENEWINCKEL, D.; KOLLE, C.; SCHMIDTKE, M. Chemically induced resistance in green bean against bacterial and fungal pathogens. Zeitschrift für. Pflanzenkrankheiten. Pflanzenschutz, Stuttgart, v. 104, n. 4, p. 599-610, 1997.

SIKKEMA, J.; BONT, J. A. de; POOLMAN, B. Mechanisms of membrane toxicity of hydrocarbons. Microbiol Revista, Groningen, v. 59, n. 2, p. 201-22, 1995.

SILVA, E. R. L. Efeito de produtos alternativos sobre Bacillus thuringiensis Subesp. Kurstaki e Trichogramma pretiosum riley (Hymenoptera: Trichogrammatidae). 2010. Tese (Doutorado em Agronomia) - Universidade Estadual de Londrina, Londrina.
SILVA, R. Z.; NEVES, P. M. O. J.; SANTORO, P. H. Técnicas e parâmetros utilizados nos estudos de compatibilidade entre fungos entomopatogênicos e produtos fitossanitários. Semina: Ciências Agrárias, Londrina, v. 26, n. 3, p. 305-312, 2005.

SIMÕES, C. M. O.; SCHENKEL, E. P.; GOSMANN, G.; MELLO, J. C. P.; MENTZ, L. A.; PETROVICK, P. R. (Org.). Farmacognosia: da planta ao medicamento. 4. ed. Porto Alegre: Editora da Universidade UFRGS; Florianópolis: Editora da UFSC, 2002.

SOSA-GÓMEZ, D. R.; DELPIN, K. E.; MOSCARDI, F.; NOZAKI, M. H. The impact of fungicides on Nomuraea rileyi (Farlow) Samson epizootics and on populations of Anticarsia gemmatalis Hubner (Lepidoptera: Noctuidae), on soybean. Neotropical Entomology, Londrina, v. 32, n. 2, p. 287-291, 2003.

TAMAI, M. A.; ALVES, S. B.; LOPES, R. B.; FAION, M.; PADULLA, L. F. L. Toxicidade de produtos fitossanitários para Beauveria bassiana (Bals.) Vuill. Arquivos Instituto Biológico, São Paulo, v. 69, n. 3, p. 89-96, 2002.

TÖFOLI, J. G. Ação de acibenzolar-S-methyl e fungicidas no controle da pinta preta do tomateiro. 2002. Dissertação (Mestrado em Agronomia) - Faculdade de Ciências Agrárias, UNESP, Botucatu.

TSUCHIYA, H.; SATO, M.; MIYAZAKI, T.; FUJIWARA, S.; TANIGAKI, S.; OHYAMA, M. Comparative study on the antibacterial activity of hytochemical flavanones against methicillin-resistant Staphylococcus aureus. Journal of Ethnopharmacol, Gifu, v. 50, n. 1, p. 27-34, 1996.

VIECELLI, C. A.; STANGARLIN, J. R.; KHUN, O. J.; SCHWAN-ESTRADA, K. R. F. Indução de resistência em feijoeiro por filtrado de cultura de Pycnoporus sanguineus contra Pseudocercospora griseola. Tropical Plant Pathology, Botucatu, v. 34, n. 2, p. 87-96, 2009.

VIECELLI, C. A.; STANGARLIN, J. R.; KUHN, O. J.; SCHWAN-ESTRADA, K. R. F. Resistance induction in bean plants against angular leaf spot by extracts from Pycnoporus sanguineus mycelium. Summa Phytopathologica, Botucatu, v. 36, n. 1, p. 73-80, 2010.

WENZEL, L. M.; BATISTA FILHO, A.; GASSEN, M. H.; ALMEIDA, A. M. B. de. Compatibilidade de Lecanicillium lecanii (Hyphomycetes), em condições de laboratório e estufa, aos agrotóxicos utilizados na cultura do crisântemo. Arquivos Instituto Biológico, São Paulo, v. 75, n. 2, p. 157-166, 2008.

YAMAMOTO, T.; MOERSCHELL, R. P.; WAKEM, L.P.; JOMAR-PANICUCCI, S.; SHERMAN, F. Strandspecificity in the transformation of yeast with synthetic oligonucleotides. Genetics, Shiga, v. 131, n. 4, p. 811819, 1992. 